\title{
The effect of taxation on tobacco consumption and public revenues in Lebanon
}

\author{
Nisreen Salti, ${ }^{1}$ Jad Chaaban, ${ }^{2}$ Rima Nakkash, ${ }^{3}$ Hala Alaouie $^{3}$
}

${ }^{1}$ Department of Economics, American University of Beirut, Beirut, Lebanon

${ }^{2}$ Department of Agriculture, Faculty of Agricultural and Food Sciences, American University of Beirut, Beirut, Lebanon

${ }^{3}$ Department of Health Promotion and Community Health, Faculty of Health Sciences, American University of Beirut, Beirut, Lebanon

\section{Correspondence to}

Dr Nisreen Salti, Department of Economics, American University of Beirut, 203 Ada Dodge Hall, PO Box 110236, Riad el Solh, Beirut 11072020, Lebanon; ns17@aub.edu.lb

Received 26 July 2012 Accepted 21 May 2013 Published Online First 20 June 2013

\begin{abstract}
Background Tobacco consumption rates in Lebanon are among the highest worldwide. The country ratified the Framework Convention on Tobacco Control in 2005. A law was passed in 2011 which regulates smoking in closed public spaces, bans advertising, and stipulates larger warnings. Despite international evidence confirming that increasing taxation on tobacco products lowers tobacco consumption, no such policy has yet been adopted: a cigarette pack costs on average US $\$ 1.50$. To date no studies in Lebanon have addressed the welfare and public finance effects of increasing taxes on tobacco products.
\end{abstract}

Methods Using the 2005 national survey of household living conditions, we estimate an almost ideal demand system to generate price elasticities of demand for tobacco. Using estimated elasticities and a conservative scenario for expected smuggling, we simulate the consumption and tax revenue effects of a change in the price of tobacco under various tax schemes.

Results Increasing taxes on all tobacco products so as to double the price of imported cigarettes would lower their consumption by $7 \%$ and consumption of domestically produced cigarettes by over $90 \%$. Young adults (ages 15-30) are more sensitive: consumption would drop by $9 \%$ for imported cigarettes and by 100\% for domestic cigarettes. Government revenues would increase by approximately $52 \%$.

Conclusions The estimated elasticities indicate that an increase in taxes on all tobacco products would lead to a reduction in consumption and an increase in government revenue. Evidence from Lebanon on the effectiveness of increased taxation may help initiate national debate on the need to raise taxes.

\section{INTRODUCTION}

Compared to other middle-income countries, in Lebanon the price of tobacco products is low and the proportion of the retail price accounted for by taxes is below average. Current government revenue from tobacco taxation consists of ad valorem excise, customs and value added taxes (VAT). Domestic and imported cigarettes are taxed at $108 \%$, shisha (water pipe) tobacco at $30 \%$, and imported tobacco products at 5\%. In addition, all tobacco products are subject to $10 \%$ VAT. Overall taxes currently account for $30-50 \%$ of retail prices, below the average collected in upper middle-income countries, in most of which taxes amount to more than $50 \%$ of the price. Locally manufactured cigarettes have a market share close to $21 \%$, and imported brands the remaining $79 \%$. Local cigarettes are priced at US $\$ 0.5 /$ pack, while the price of foreign brands averages US $\$ 1.7$, compared to US $\$ 2.5 /$ pack in upper middle-income and US\$5/pack in high-income countries. ${ }^{1}$

According to recent figures, ${ }^{2}{ }^{3}$ approximately $42.9 \%$ of Lebanese male adults and $27.5 \%$ of Lebanese female adults are cigarette smokers. Women have the highest female smoking rate in the region. ${ }^{2}{ }^{4}$ With consumption reaching 12.4 packs per person per month, Lebanese monthly consumption of cigarette packs is 12 times that of Singapore and three times that of Syria. ${ }^{1}$ Smoking is also prevalent among youth, with rates of $14.8 \%$ for males and $6.7 \%$ for females. ${ }^{2}$ Shisha (also known as waterpipe) smoking prevalence among youth (ages 13-15) is even higher than that of cigarettes, with $64.1 \%$ of young males and $54.7 \%$ of young females smoking. ${ }^{5}$ The total economic burden of tobacco consumption in Lebanon has been estimated at around US $\$ 350$ million per year, or $1.2 \%$ of GDP.

Across countries, evidence shows that tobacco taxation can simultaneously increase government tax revenues and decrease consumption. ${ }^{7}$ A $10 \%$ increase in the price of cigarettes is expected to reduce demand by an average of $4-6 \%$ in highincome countries and by $2-7 \%$ in low and middle-income countries. Studies have also shown that children and adolescents are more responsive to price increases than adults. ${ }^{8} \mathrm{~A}$ decrease in tobacco consumption will reduce the health burden of smoking by decreasing the direct cost of medical treatment and the indirect cost of lost productivity associated with morbidity and mortality. ${ }^{9}$

The inelasticity of demand for tobacco among adults generally means that an increase in taxes, while reducing consumption, also generates government revenue. This has been the experience in South Africa between 1993 and 2007. An increase of $146 \%$ in real retail prices resulted in a $48 \%$ drop in per capita consumption of cigarettes and a $215 \%$ increase in excise revenues. ${ }^{10}$ Similarly, in Hungary the increase in the tax on cigarettes between 1997 and 1999 resulted in higher tax revenues. ${ }^{11}$

Lebanon ratified the Framework Convention on Tobacco Control in 2005 and the Lebanese parliament passed a law in August 2011 that forbids smoking in closed public places, bans the advertising and promotion of tobacco products, and stipulates larger textual and pictorial warnings. However, increasing taxation on tobacco products remains low on the public health agenda. To date there have been no studies in Lebanon that address the welfare and public finance effects of increasing taxes on tobacco products. This paper uses data on the expenditures of households: (a) to estimate own- and cross-price elasticities of demand for 
tobacco products; (b) to simulate, for a variety of tax rates, change in consumption; and (c) to estimate the resulting change in government revenue.

\section{METHODS}

We use an almost ideal demand system (AIDS) model to estimate own- and cross-price elasticities of demand for tobacco-related products. We use the detailed expenditure data collected in the expenditure module of the 2005 Household Living Conditions Survey for Lebanon to estimate the characteristics of demand and spending for different household expenditure categories. The survey does not include price data, but does contain a price index for each of five categories of goods and services for each of the six Mohafazas (provinces) of Lebanon. The index is calculated by the Central Administration for Statistics for the purpose of quantifying regional differences in prices by category of goods and services. We use this regional variation in the price indexes across Mohafazas to estimate own- and cross-price elasticities of demand.

In the context of the regulated market for tobacco in Lebanon, where tobacco products have uniform pricing across all regions, we use variations in the regional price indexes for other categories of consumption goods and services to estimate elasticities, assuming any differences in the consumption baskets across regions result from differences in relative prices. Once we have estimated price elasticities of demand, we can simulate the effect on quantity demanded of increases in the tax rate on tobacco products. We use a methodology similar to that of Salti and Chaaban ${ }^{12}$ where we estimate the change in household expenditure following the change in prices brought about by the tax. The methodology consists of estimating own- and crossprice (Hicksian) elasticities of demand, by evaluating the changes in quantities given the differences in price levels.

\section{Data and empirical strategy}

The 2005 survey of household living conditions was administered by the public statistical agency (The Central Administration of Statistics). The sample design was nationally representative with a large sample size. Four survey forms were used in the multi-purpose survey: two daily expenditure forms, another expenditure form and a 'household characteristics and living conditions' form. Data on household characteristics and living conditions were collected from 13003 households, while expenditure data were collected from a subsample of 7431 households. In diary questionnaires, the main respondent as well as every household member above 15 years of age reported all expenditures that occurred over 2 weeks. Expenditure on non-food items was collected for the previous 3 months or the previous year depending on the type of commodity. Due to data confidentiality constraints, individual prices and quantities were not made available to researchers, however total expenditure for each consumption category was provided. Also, Paasche price indexes for each of the six Mohafazas and for each major expenditure category were made available. In our empirical model below, we present a simple technique for dealing with this limited price information, by relying on spatial price variations to estimate demand parameters.

The AIDS developed by Deaton and Muellbauer ${ }^{13}$ is one of the most widely used techniques to estimate demand systems in the economic literature. It provides a practical way of modelling expenditures with several commodities and satisfies basic economic assumptions on consumer behaviour. It is also simple and straightforward to use. The AIDS model has been employed to estimate elasticities of demand for tobacco products in other countries, including Vietnam, ${ }^{14}$ Poland $^{15}$ and the UK. ${ }^{16}$ Technical details on the empirical model specification are available from the authors.

\section{RESULTS}

Our study focuses on the household consumption of tobacco products, comprising mainly imported cigarettes, local cigarettes and shisha tobacco. Total spending on these products reached US\$553 million in 2010, with US\$512 million spent on 307 million packs of imported cigarettes (table 1).

The government of Lebanon currently applies three taxes to tobacco products: an excise tax on imports (108\% for imported cigarettes, $30 \%$ for shisha tobacco) and on local cigarettes (108\% on factory prices); a 5\% customs tax on imported tobacco products; and 10\% VAT on all local and imported tobacco. The customs tax is applied on the price including the excise tax, and the VAT is applied on the price including both the excise and, when applicable, the customs tax. Note that the excise rate per pack of cigarettes in Lebanon is still below the minimum excise burden found in most comparable countries. ${ }^{17}$

Within the context of the high smoking prevalence in the country, the Lebanese government currently collects approximately US\$230 million per year in tobacco tax revenue. This excludes profits accrued by the national public tobacco production and trade monopoly (the Regie) and is affected by crossborder smuggling, which is estimated at $22.5 \%$ of national consumption expenditure. ${ }^{1}$

To simulate the impact of increasing the price of tobacco products on national consumption and public revenue, we estimated the relevant own- and cross-price demand elasticities for the above-mentioned products (table 2). The elasticities are derived from the AIDS model parameter estimates (technical

Table 1 Consumption, taxation and government revenue

\begin{tabular}{|c|c|c|c|}
\hline & $\begin{array}{l}\text { Local } \\
\text { cigarettes }\end{array}$ & $\begin{array}{l}\text { Imported } \\
\text { cigarettes }\end{array}$ & $\begin{array}{l}\text { Shisha } \\
\text { tobacco* }\end{array}$ \\
\hline Retail price/pack, US\$† & 0.5 & 1.67 & 2.00 \\
\hline Quantity (in packs)‡ & 81500000 & 306800000 & 294000 \\
\hline Total expenditure & US\$40 750000 & US\$512 356000 & US\$588000 \\
\hline \multicolumn{4}{|l|}{ Tax value per pack, US\$§ } \\
\hline Excise & 0.24 & 0.75 & 0.40 \\
\hline Customs & 0.00 & 0.03 & 0.07 \\
\hline VAT & 0.02 & 0.07 & 0.13 \\
\hline $\begin{array}{l}\text { Total tax valuel } \\
\text { pack }\end{array}$ & 0.26 & 0.86 & 0.60 \\
\hline $\begin{array}{l}\text { Tax percentage of } \\
\text { retail price }\end{array}$ & $52 \%$ & $51 \%$ & $30 \%$ \\
\hline \multicolumn{4}{|l|}{ Government revenue } \\
\hline Excise & US\$19 235000 & US\$195 780000 & US\$100000 \\
\hline Customs & - & US\$9 064000 & US\$17 000 \\
\hline VAT & US\$1 781000 & US\$18 128000 & US\$33 000 \\
\hline Total & US\$21 016000 & US\$222972000 & US\$150000 \\
\hline
\end{tabular}

${ }^{*} \mathrm{~A}$ pack of shisha tobacco typically contains $50-250 \mathrm{~g}$ of tobacco. The tobacco is commonly packed in cardboard boxes of various sizes, but is also sold in jars and tin cans. $^{18}$

tThe retail price per pack is obtained from interviews conducted with key informants by the authors.

‡The total quantity consumed per product is calculated based on the household survey and Chaaban et al. ${ }^{6}$

$\S$ The tax value per pack is based on the import cost, insurance and freight (CIF) prices for imported tobacco products (obtained from the Customs Administration at the Ministry of Finance) and the factory prices for local tobacco (obtained from the Regie at the Ministry of Finance)

१The total tax refers to the combination of excise, custom and VAT taxes. 
Table 2 Estimated own- and cross-price elasticities of demand for tobacco products in Lebanon

\begin{tabular}{lrll}
\hline & $\begin{array}{l}\text { Local } \\
\text { cigarettes }\end{array}$ & $\begin{array}{l}\text { Imported } \\
\text { cigarettes }\end{array}$ & $\begin{array}{l}\text { Shisha } \\
\text { tobacco }\end{array}$ \\
\hline Local cigarettes & $-1.54(0.045)$ & & \\
Imported cigarettes & $0.13(0.005)$ & $-0.22(0.0138)$ & \\
Shisha tobacco & $-0.37(0.054)$ & $0.15(0.009)$ & $-1.45(0.007)$ \\
\hline SD in parentheses & & &
\end{tabular}

SD in parentheses.

details on the estimation are available from the authors). These elasticities are central to mapping the impact of higher prices on the quantities of packs consumed, and to incorporating the substitution possibilities that consumers might engage in across tobacco products. The AIDS model estimates Hicksian elasticities of demand, which, by definition, yield symmetrical crossprice elasticities. Our elasticity estimates are in line with international findings, ${ }^{7}$ as we find that the own-price elasticity for imported cigarettes is -0.22 (ie, for every $10 \%$ increase in imported cigarette prices, quantity consumed would drop by $2.2 \%$, which shows an inelastic relationship). This result is not very far from the estimated elasticities for Egypt ${ }^{19}(-0.39)$ and Turkey $^{20}(-0.41)$. Other studies that have used an AIDS model to estimate elasticities found elasticities in the range of -0.76 (in Poland) ${ }^{15}$ to -0.53 (in Vietnam). ${ }^{14}$

Using these elasticities, we simulate the impact on tobacco consumption and government revenues of increasing taxes on tobacco products. To illustrate this, two reforms were chosen:

- Raising the ad valorem excise tax by $50 \%$

- Enacting a new per-pack excise tax, which could be earmarked for public health projects, as follows: US\$0.17/pack on local cigarettes, US $\$ 1.00 /$ pack on imported cigarettes, and US\$0.33/pack on shisha tobacco packs.

Given that increasing taxes would raise prices, we incorporate an extreme scenario of smuggling increasing by $100 \%$ (from $22.5 \%$ to $45 \%$ of consumption). This echoes government fears of cross-border smuggling into Lebanon from neighbouring countries where tobacco products are cheaper, especially Syria, following a local price increase. The scenarios are summarised in table 3.

Enacting the above tax reforms would lower the consumption of local cigarette by $93 \%$, imported cigarettes by $7 \%$, and shisha tobacco by $25.5 \%$ (table 4 ). The prices of imported cigarettes would increase from an average of US\$1.67/pack to around US\$3.2/pack, which would be more in line with international prices, with tax shares increasing from the current $50 \%$ to $73 \%$ of retail price for imported cigarettes.

Table 3 Simulation scenarios for increasing tobacco taxes

\begin{tabular}{llll}
\hline & \multicolumn{3}{l}{$\%$ Increase in ad valorem tax rates } \\
\cline { 2 - 4 } & $\begin{array}{l}\text { Local } \\
\text { cigarettes }\end{array}$ & $\begin{array}{l}\text { Imported } \\
\text { cigarettes }\end{array}$ & $\begin{array}{l}\text { Shisha } \\
\text { tobacco }\end{array}$ \\
\hline $\begin{array}{l}\text { Excise } \\
\text { Customs }\end{array}$ & $50 \%$ & $50 \%$ & $50 \%$ \\
VAT & $0 \%$ & $0 \%$ & $0 \%$ \\
New excise tax per & 0.17 & 1.00 & $0 \%$ \\
pack, US\$ & & $100 \%$ & 0.33 \\
Smuggling rate increase & & & \\
\hline
\end{tabular}

Table 4 Simulation results: impact on prices and consumption

\begin{tabular}{llll}
\hline & $\begin{array}{l}\text { Local } \\
\text { cigarettes }\end{array}$ & $\begin{array}{l}\text { Imported } \\
\text { cigarettes }\end{array}$ & $\begin{array}{l}\text { Shisha } \\
\text { tobacco }\end{array}$ \\
\hline $\begin{array}{l}\text { Tax value per pack, US\$ } \\
\quad\end{array}$ & 0.35 & 1.13 & \\
$\quad$ Excise & 0.00 & 0.03 & 0.60 \\
$\quad$ Customs & 0.06 & 0.18 & 0.07 \\
$\quad$ VAT & 0.17 & 1.00 & 0.33 \\
$\quad$ New excise tax per pack & 0.58 & 2.34 & 1.19 \\
$\quad$ Total tax value/pack & $72 \%$ & $73 \%$ & $44 \%$ \\
Tax percentage of retail price & $72 \%$ & 2.00 \\
Retail price/pack, US\$ & 0.50 & 1.67 & 0.59 \\
Tax increase/pack, US\$ & 0.32 & 1.49 & 2.67 \\
New retail price, US\$ & 0.80 & 3.21 & $34 \%$ \\
\% Change in price & $61 \%$ & $92 \%$ & \\
Change in consumption & & & \\
$\quad$ Local cigarettes & $-93.5 \%$ & & \\
Imported cigarettes & $-7.0 \%$ & & \\
$\quad$ Shisha tobacco & $-25.5 \%$ & & \\
\hline
\end{tabular}

\section{Tobacco consumption among young adults}

We also estimate the price elasticities of demand for young adults. Since consumption expenditure data are reported only at the household level, we estimate the above demand equations for a subgroup defined as household heads aged 15-30. Our elasticities estimates show that the own-price elasticity for imported cigarettes among young adults is -0.28 , compared to -0.22 for the overall population. This slight decrease indicates that young adults are slightly more price responsive than the rest of the Lebanese population. While the own-price elasticity for local cigarettes remains the same, the elasticity of shisha tobacco is much higher in absolute value among young adults ( -2.17 compared to -1.45 as estimated above).

Our simulation suggests that consumption of local cigarettes among young adults would drop by $100 \%$ (compared to $93 \%$ for the entire population), that of imported cigarettes by $9 \%$ (compared to $7 \%$ overall), and that of shisha tobacco by $37 \%$ (26\% overall). These simulation results indicate that young adults would reduce their tobacco consumption more than the overall Lebanese population.

\section{Impact on tax revenues}

Given that prices increase more than consumption decreases, the net revenue impact on government finances is positive: increasing tobacco taxes would generate US\$127 million in additional public revenues, an increase of about $52 \%$ (table 5). This is despite the extreme scenario of a presumed doubling in smuggling activity as a result of higher prices.

The tobacco tax reform would then operate on two levels: increasing the final price of tobacco products, and increasing the share of taxes in the final retail price. From a current average price of US $\$ 1.67 /$ pack for imported cigarettes, this reform would increase it to US $\$ 3.2 /$ pack, higher than in other comparable upper middle-income countries, which have an average price of US $\$ 2.48$, and closer to Turkey's average price of US $\$ 3.15 .^{21}$ There is definitely still some room to increase prices even more (for example, closer to higher-income countries' average of US $\$ 5 /$ pack). Our simulations show that a US $\$ 5 /$ pack price for imported cigarettes would lower consumption by almost 20\%. 
Table 5 Simulation results and impact on government revenue

\begin{tabular}{|c|c|c|c|}
\hline & Local cigarettes & Imported cigarettes & Shisha tobacco \\
\hline Smuggling rate (\% consumption) & & $45 \%$ & $45 \%$ \\
\hline \multicolumn{4}{|l|}{ Government revenues } \\
\hline Excise & US\$1 881000 & US\$176 659000 & US\$72000 \\
\hline Customs & - & US\$5 452000 & US\$8000 \\
\hline VAT & US\$304 000 & US\$28 571000 & US\$23000 \\
\hline New tax per pack & US\$903 000 & US\$156874 000 & US\$40 000 \\
\hline Total & US\$3 089000 & US\$367 557000 & US\$143000 \\
\hline Change in government revenues & (US\$17 927000$)$ & US\$144 585000 & (US\$7000) \\
\hline Change in government revenues & $-85 \%$ & $65 \%$ & $-4 \%$ \\
\hline Total change in government revenues from all tobacco products & US\$126 651000 & & \\
\hline Percentage change in government revenues from all tobacco products & $52 \%$ & & \\
\hline
\end{tabular}

Regarding the tax burden, the suggested tax reform would increase the share of taxes of the average retail price for imported cigarettes from $51 \%$ to $73 \%$, a ratio much higher than in upper middle-income (54\%) and high-income countries $(63 \%)$, and equal to the rate applied in Turkey. ${ }^{20}$

\section{DISCUSSION}

Taxation of tobacco products has been shown to be an effective tool for controlling tobacco use. Article 6 of the Framework Convention on Tobacco Control requires ratifying countries to consider taxation as one of the national strategies of tobacco control. Despite the fact that Lebanon has recently implemented a tobacco control policy, increasing taxation is absent from the policy agenda, and tobacco products are very cheap. Research on tobacco industry documents suggests that transnational tobacco companies in Lebanon have lobbied over an extended period of time to influence tobacco taxation policy. ${ }^{22}$ Many of the arguments against increasing taxes encourage fears of increased smuggling, ${ }^{23}$ when in fact much evidence suggests that the tobacco industry is actually complicit in smuggling. ${ }^{24}$

This study shows that a reduction in consumption will result from an increase in price, and that younger households are more sensitive to price increases, corroborating other evidence on the effectiveness of increased taxes in limiting consumption among youth. ${ }^{25}$ We also find a positive net impact on government revenue (increasing by 52\%) despite an assumption of doubling in smuggling. The results are qualitatively similar to the findings from other simulations of the effect of taxing tobacco. ${ }^{192026}$

\section{Limitations}

Application of the AIDS model to our data has some limitations. As stated earlier, our elasticities are estimated assuming any differences in the consumption baskets across regions result from differences in relative prices, and the underlying demand function is assumed to be the same for all households within a province. It should also be noted that our model relies on a short-term framework, where we focus on the direct effects of a rise in prices on household demand. Incorporating other effects would require detailed data on the income and saving patterns of households, in addition to specific assumptions on how increased government revenue from the tax would affect households' incomes and overall expenditures. We cannot incorporate these effects in our analysis, as we do not have data on household income and saving. For this, we assume that households' nominal income is fixed in the simulation period. This assumption, similarly used by Bibi and Duclos ${ }^{27}$ in their analysis of indirect tax reforms in Tunisia, is not too constraining as we are chiefly interested in the short-term consumption effects of a change in the price of tobacco products.

Because the data are at the household level, we are unable to identify individual smokers in the household or therefore to consider the household level of consumption of tobacco products. By the same token, we do not know the age of smokers. Instead, we identify youth as those households where the household head is young (aged 15-30).

The expenditure data do not provide information on tobacco products consumed at other commercial establishments such as restaurants and cafes. Our measures of spending on shisha tobacco are therefore likely an underestimate the total spending on shisha tobacco by households.

\section{CONCLUSION}

This is the first study that provides evidence for the effectiveness of increasing taxation on tobacco products in Lebanon. The estimated elasticities indicate that the demand for imported cigarettes is price inelastic, and that locally produced cigarettes and shisha tobacco are substitutes for imported cigarettes. Therefore, a policy of increasing taxes on all tobacco products would lead to a reduction in consumption and, because most tobacco products are imported, an increase in government revenues. These findings can be used in a campaign to encourage the Lebanese government to increase the tax on tobacco. Some of the funds raised through taxation could be used to finance tobacco control, prevention and cessation programmes.

\section{What this paper adds}

- This paper adds to the growing international evidence on the effectiveness of taxing tobacco products as a tobacco control strategy.

- This is the first research study to simulate increasing taxes in Lebanon, which would result in lower consumption and higher government revenue.

- It provides recommendations for action and crucial evidence to support a policy to increase taxation in Lebanon and other countries which are considering similar policies. 
Contributors NS and JC cleaned up the household survey data and applied the AIDS model to estimate the elasticities. HA helped with the literature review and the background section on Lebanon. RN suggested the policy package the paper proposes and situated the study in the taxation and estimation literature.

Funding This work was supported by IDRC grant number 105136-005.

Competing interests None.

Provenance and peer review Not commissioned; externally peer reviewed.

\section{REFERENCES}

1 Eriksen M, Mackay J, Ross H. The tobacco atlas. 4th edn. Atlanta, GA: American Cancer Society; New York, NY: World Lung Foundation, 2012.

2 Sibai A, Hwalla N. Non-communicable disease and behavioral risk factor survey. Final report submitted to the World Health Organization-Lebanon office, 2010.

3 Saade G. Linking Global Youth Tobacco Survey (GYTS) to the WHO Framework Convention on Tobacco Control (FCTC): the case for Lebanon. Prev Med 2005;47: S15-19.

4 World Health Organization. WHO Framework Convention on Tobacco Control. Geneva, Switzerland: World Health Organization, 2005.

5 Saade $G$, Abou Jaoude $S$, Afifi $R$, et al. Patterns of tobacco use: results from the 2005 Global Youth Tobacco Survey in Lebanon. EMHJ 2008:14:1280-9.

6 Chaaban J, Naamani N, Salti N. The economics of tobacco in Lebanon: an estimation of the social costs of tobacco consumption. Beirut: American University of Beirut Issam Fares Institute, 2010. http://www.aub.edu.Ib/ifi/public_policy/rapp/ rapp_research/Pages/economics_of_tobacco_lebanon.aspx

7 IARC. IARC Handbooks of Cancer Prevention. Tobacco control, vol. 14: effectiveness of tax and price policies for tobacco control. Lyon, France: IARC, 2011.

8 Gruber J, Sen A, Stabile M. Estimating price elasticities when there is smuggling: the sensitivity of smoking to price in Canada. J Health Econ 2003;22:821-42.

9 Lewis S, Arnott D, Godfrey C, et al. Public health measures to reduce smoking prevalence in the UK: how many lives could be saved? Tob Control 2005; 14:251-4.

10 Van Walbeek C.Tobacco excise taxation in South Africa. South Africa: World Health Organization; 2003. http://www.who.int/tobacco/training/success_stories/en/ best_practices_south_africa_taxation.pdf
11 Yurekli A. Tobacco control policy: the challenge of raising tobacco taxes, global, regional and the Hungarian experience. World Bank presentation, Tobacco dissemination meeting; 2001, Budapest, Hungary.

12 Salti N, Chaaban J. The poverty and equity implications of a rise in the value added tax. Mid East Dev J 2010;2:1-18.

13 Deaton A, Muellbauer J. An almost ideal demand system. Amer Econ Rev 1980;70:312-26

14 Eozenou P, Fishburn B. Price elasticity estimates for cigarette demand in Vietnam. DEPOCEN working paper series 2009/05, 2009.

15 Gardes F, Starzec C. Are tobacco and alcohol expenditures price-elastic? The case of Poland consumption. CERSEM working paper, Universite Paris I, 2004.

16 Cullum P, Pissarides C. The demand for tobacco products in the UK. Government Economic Service Working Paper No. 150, 2004.

17 Blecher E. Targeting the affordability of cigarettes: a new benchmark for taxation policy in low-income and-middle-income countries. Tob Control 2010;19:325-30.

18 Nakkash R. Khalil, J. Health warning labeling practices on narghileh (shisha, hookah) waterpipe tobacco products and related accessories. Tob Control 2010;19:235-9.

19 Nassar H. Economics of tobacco in Egypt: a new analysis of demand. HNP discussion papers, Economics of Tobacco Control Paper No. 8, March 2003.

20 Onder Z. Economics of tobacco control in Turkey: new evidence and demand estimates. HNP discussion papers No. 2, 2002.

21 World Health Organization. WHO technical manual on tobacco tax administration, 2010. http://www.who.int/tobacco/publications/economics/tax_administration/en/ index.html

22 Nakkash R. Tobacco industry strategies in Lebanon: an analysis of internal tobacco industry documents. Thesis (DrPH), London School of Hygiene and Tropical Medicine, 2007.

23 Joossens L, Raw M. Cigarette smuggling in Europe: who really benefits? Tob Control 1998; 7:66-71.

24 Nakkash R, Lee K. Smuggling as the key to a combined market: British American tobacco in Lebanon. Tob Control 2008:17:324-31.

25 Chaloupka F, Grossman M. Price, tobacco control policies and youth smoking. NBER working paper 5740, 1996.

26 Jiménez-Ruiz JA, Sáenz de Miera B, Reynales-Shigematsu $L M$, et al. The impact of taxation on tobacco consumption in Mexico. Tob Control 2008;17:105-10.

27 Bibi S, Duclos JY. Poverty-decreasing indirect tax reforms: evidence from Tunisia. Int Tax Public Finan 2007;14:165-190. 